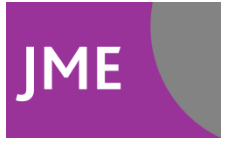

\title{
Informed consent for the study of retained tissues from postmortem examination following sudden infant death
}

J G Elliot, D L Ford, J F Beard, et al.

$J$ Med Ethics 2008 34: 742-746

doi: 10.1136/jme.2007.021428

Updated information and services can be found at:

http://jme.bmj.com/content/34/10/742.full.html

Topic collections Articles on similar topics can be found in the following collections

Epidemiologic studies (24256 articles)

Child health (26618 articles)

Informed consent (1077 articles)

Legal and forensic medicine (4088 articles)

Notes

To request permissions go to:

http://group.bmj.com/group/rights-licensing/permissions

To order reprints go to:

http://journals.bmj.com/cgi/reprintform

To subscribe to BMJ go to:

http://journals.bmj.com/cgi/ep 


\title{
Informed consent for the study of retained tissues from postmortem examination following sudden infant death
}

\author{
J G Elliot, ${ }^{1}$ D L Ford, ${ }^{2}$ J F Beard, ${ }^{3}$ K N Fitzgerald, ${ }^{2}$ P J Robinson, ${ }^{4}$ A L James ${ }^{1,5}$
}

${ }^{1}$ West Australian Sleep

Disorders Research Institute, Sir Charles Gairdner Hospital, Nedlands, Western Australia, Australia; ${ }^{2}$ SIDS and Kids Victoria, Malvern, Victoria, Australia; ${ }^{3}$ Victorian Institute of Forensic Medicine, South Bank, Victoria, Australia; ${ }^{4}$ Department of Respiratory Medicine, Royal Children's Hospital, Parkville, Victoria, Australia; ${ }^{5}$ School of Medicine and Pharmacology, University of Western Australia, Nedlands, Western Australia, Australia

Correspondence to:

Mr J Elliot, West Australian

Sleep Disorders Research

Institute, Sir Charles Gairdner

Hospital, Nedlands, Western

Australia 6009, Australia; john.

elliot@health.wa.gov.au

KNF is deceased.

Received 30 April 2007

Revised 23 December 2007

Accepted 9 January 2008

\begin{abstract}
Objective: To develop an approach for seeking informed consent to examine tissues retained from a previous study of sudden infant death syndrome (SIDS) as part of a study on asthma, and to document responses and participation rate.
\end{abstract}

Design: Pilot open-ended approach to 10 volunteer SIDS parents, followed by staged approach (newsletter, mail and telephone call) to seek consent from the target SIDS families for the asthma study.

Participants: Parents $(n=10)$ of SIDS infants known to SIDS and Kids Victoria and parents of SIDS infants ( $n=107)$ from the 1991-2 SIDS in Victoria case-control study.

Main outcomes: Qualitative responses of the piloted parents and study parents, and participation rates.

Results: The pilot group responses were used to refine the written material to be provided. Of the 72 families for which contact details were available, 45 gave verbal consent for contact by the Victorian Institute of Forensic Medicine regarding the asthma study, three refused and 24 did not respond to two letters. Thirty-three completed consent forms, all positive for participation in the asthma study, giving a positive response rate of 73\% (33/45).

Conclusions: The use of postmortem tissue for research is acceptable to the next of kin when an approach is sensitive to their concerns and needs and is made by experienced counsellors from a familiar organisation. Despite the painful memories evoked by the approach of the research group, the acceptance rate among those who could be contacted was high.

The use of postmortem tissues for research raises a number of issues regarding consent, ownership, family grief and cultural and religious beliefs and has been the subject of considerable scrutiny. Publicised inquiries into the retention and use of postmortem tissues have raised a number of issues, particularly that of informed consent. ${ }^{1-3}$ Australian legislation states that authority for autopsy is authority for retention of tissue, removed for the purpose of the autopsy, for medical, scientific or therapeutic purposes. This followed the recommendations of the Australian Law Reform commission in 1977, which explicitly stated that the public benefits flowing from this approach outweighed the need to obtain individual consent. Clearly, by the 1990s this was out of step with community attitudes. The Royal College of Pathologists of Australasia published guidelines on autopsy and the use of tissues removed at autopsy in $1994 .{ }^{4}$ The reports from these inquiries have led to recommendations and changes to the
Coroner's Act, which require more stringent consent protocols and explicit documentation for the use of tissues taken at autopsy. ${ }^{5}$

Although informed consent for the use of postmortem tissues for research may be obtained around the time of death, the further use of such tissues for the same or new projects raises other questions. Subsequent studies related to the initial aims of the research require separate ethics committee approval but not necessarily new approaches to the next of kin. ${ }^{7}$ However, studies that are outside the aims of the original research may require ethical approval and further approaches to next of kin, which may incur considerable expense and inconvenience to researchers and subjects. ${ }^{8}$ Little is known about the impact and likely success rate of these further approaches.

In 1991, the Centre for the Study of Mothers' and Children's Health and the Sudden Infant Death Research Foundation (SIDRF) (now known as SIDS and Kids, Victoria) commenced a casecontrol study of the epidemiology of SIDS in Victoria.9 In 1995, the Ethics Committee of the Victorian Institute of Forensic Medicine (VIFM) granted permission for the further use of samples of formalin-fixed lung tissue from the 1991-2 SIDS study for research into airway dimensions in SIDS. ${ }^{10-12}$ In 2003, a new study was proposed to use the lung tissue samples to examine airways in relation to parental history of asthma-data that had been collected at the time of the original study. Since the study of asthma was not directly related to the ethics committee approval given for the 1991 SIDS study, the VIFM determined that a further approach to the parents was needed if the stored tissues were to be used. In order to undertake the study of asthma in tissues from SIDS infants, we found ourselves with an ethical dilemma. On the one hand, approaching parents would be a distressing reminder of their child's death. On the other, these parents had previously given consent to participate in a study of SIDS and were well known to SIDS and Kids, and many had expressed the view that participation in research was a good outcome from the tragic event. VIFM had the view that ethical approval for the asthma project had not been granted. Therefore, it was decided that we should explore the most appropriate method of a further approach to parents for consent for future research. The authors made use of the close association between SIDS and Kids and the pilot families to develop the approach. It was decided that a structured approach would be 
devised, based on a pilot study in a group of parents known to SIDS and Kids. This paper describes this process, parental responses and eventual response rate.

\section{METHODS}

The 1991-2 case-control study of SIDS in the state of Victoria identified families who had experienced a child's death thought to be due to SIDS. Sources included ambulance and police officers, paediatric emergency nursing staff and SIDS grief counsellors. The families were invited to participate in a formal research interview. We administered standardised questionnaires relating to demographics, socioeconomic background, the pregnancy and birth of the infant, and the medical histories of the infant and parents, including cigarette smoking and parental history of asthma. Participants gave written consent at the time for the questionnaire data to be used in other ethically approved research studies, provided they were related to SIDS.

\section{Postmortem examination}

In all cases of sudden unexplained death in Victoria, a postmortem examination is undertaken under the direction of the state coroner. At the time, a diagnosis of SIDS was made when postmortem examination and circumstances surrounding death did not suggest an alternative cause. Tissue blocks, fixed in formalin and processed into paraffin wax, were sectioned, stained and examined microscopically. As an accreditation requirement, tissue blocks are stored for at least 20 years.

\section{Advisory group}

Consent from the 1991 study did not encompass studies focused on diseases other than SIDS, such as that proposed in the 2003 asthma study. To establish a protocol for further contact with parents from the original 1991 study, an advisory group was established, consisting of representatives from SIDS and Kids Victoria, VIFM and the asthma research group. Several documents were drafted: an introductory letter from the chief executive officer (CEO) of SIDS and Kids Victoria; an information sheet outlining the research, and consent forms for the current research study and for possible future studies. In addition, an article in the 2003 SIDS and Kids newsletter outlined the asthma study and indicated the intention to contact families from the original study.

\section{Pilot group of SIDS families}

Parents of 10 SIDS babies who were not part of the 1991 study and who agreed to participate took part in a 30-45-minute interview with an experienced counsellor at SIDS and Kids Victoria. Five parents were consulted about their experience and knowledge of the autopsy processes following the death of their infant, and in this context the issue of tissue retention was considered. The aim was to explore parents' understanding, knowledge and concerns about these issues and their opinions and concerns about the proposed research. Subsequently, another five parents were asked to comment on the proposed documentation and the intended approach in general. The aim of the consultation was to assess likely responses to the proposed project, to identify common themes of importance to bereaved parents in relation to research in general and to the asthma study in particular (including postmortem examination and the use of tissue samples for research) and to assess the impact and usefulness of the various documents. From this process, the advisory group adopted a structured approach to parents aimed at minimising initial impact and offering prompt advice and counselling.

\section{Contacting families of the 1991-2 SIDS case-control study}

The families from the 1991-2 study were located using SIDS and Kids databases including services and family case lists and contact numbers for extended family members, and the telephone book. The devised approach consisted of a number of steps. First, a short letter was sent to parents from the CEO of SIDS and Kids introducing the asthma study and included notification of a follow-up telephone call from SIDS and Kids within 2 weeks. A contact telephone number of a counsellor from SIDS and Kids for immediate advice or questions was provided. Second, the follow-up telephone call was made and agreement was requested for contact from a VIFM researcher to discuss further use of tissue samples retained at postmortem and used in the original SIDS study. Qualitative information was recorded on the responses of parents to this contact. This was open ended and included reactions and knowledge of retained tissues after postmortem examinations, willingness to participate, reaction to ongoing research and specific information that the parents would like to receive. Third, an information sheet and consent forms regarding the asthma study were posted to parents if they wished to receive them. Written consent was requested for participation in the asthma study or participation in future, unspecified studies, or both. In either case, parents could choose to be contacted about future studies, notified about future studies or not contacted at all in the future. Parents were also given the option to receive written information about the coronial process, including autopsy.

\section{RESULTS}

\section{Pilot group of SIDS parents}

Ten parents were approached to consult on the study. None had previously been involved in research using retained tissues, and all raised a number of concerns. Two who knew that autopsies were conducted in cases of SIDS were unaware that tissue had been retained. Their reaction to this information progressed from shock, feelings of exclusion regarding the retention of tissue and feelings of being offended, to expression that through the research, their infant's death might make a positive contribution to helping others. The latter was expressed as a wholehearted acceptance of the need for research and willingness to participate. Specific feedback from the pilot parents was used to develop the documentation to be used in the approach regarding future research. Concerns were expressed about implications for parents who were smokers at the time of their child's death. Issues regarding where and how much tissue was stored and conditions for its use were also raised. Parents also requested information about clinically relevant research findings, particularly in relation to the death of their infant. There was uniform agreement that the correspondence should be simplified as much as possible. It was also decided that parents must have a choice about whether or not they wanted to receive a plain English information sheet about the coronial process relating to the postmortem examination. In response to the concerns of the pilot group, changes were made to the documentation, including the removal of parental smoking from the study title.

\section{Parental contact}

SIDS and Kids had contact details of 30 (28\%) families from the 1991-2 research cohort, and a further 42 (39\%) contact details 
were obtained from other sources (fig 1). Thirty-five families $(33 \%)$ could not be located. Seventy-two families (67\%) were sent an initial letter from the CEO of SIDS and Kids introducing the research. Of these, 45 families (62\%) gave verbal permission for their contact details to be given to VIFM so they could be contacted to discuss the possibility of consent for the use of the retained tissues. This represented $42 \%$ of the original cohort. Three families refused permission and 24 did not respond to two letters and could not be contacted by telephone, suggesting that their contact details were no longer correct.

\section{Parent responses and consent rate}

The outcomes of interviews with the researchers from VIFM are summarised in table 1. Surprisingly, only two parents expressed the degree of distress anticipated by the pilot group of parents. One of these agreed to participate in the study. Two others expressed minor distress. Seven subjects requested that information regarding the autopsy process not be sent to them and 17 indicated that they wanted to receive all documentation. Nineteen parents were "keen to help" and 19 stated at the initial telephone call that they would participate in the study. Thirty-nine parents expressed willingness to participate in the asthma study and possibly future studies at the time of interview, and 45 were sent documentation. Thirty-three families returned the consent forms to VIFM, all giving consent for the use of retained tissues in the present study. Twenty-six families gave consent for future studies and six did not return documentation and could not be contacted further (fig 1).

\section{DISCUSSION}

We sought consent for the use of retained autopsy tissue from families who had experienced the death of an infant from SIDS more than a decade earlier. Our intention was to link histological findings from the tissues to epidemiological data from the 1991-2 SIDS in Victoria case-control study. Since the initial study, there has been considerable public debate about the use of autopsy tissue for research. We derived a method of approaching families from the 1991 study to address these issues and minimise anticipated distress. As far as possible, potential concerns were identified in a pilot group of SIDS parent advisers by using experienced SIDS and Kids bereavement counsellors and the family liaison coordinator from VIFM. The study was introduced by a figure familiar to the families (the CEO of SIDS and Kids) and information was provided through the SIDS and Kids newsletter, which the families had previously received.

Of the 39 families that could be contacted, $85 \%$ agreed to the use of retained tissues. This shows that in this group of unexplained deaths, where there was informed consent and an opportunity to decline participation, most families were willing for retained tissue to be used for the purpose of research. It would probably not be justified to extrapolate the results to families of children who die from other causes, such as drowning or stillbirth. Rodriguez-Villar and colleagues obtained a 59\% donation rate from the next of kin for corneas and other tissues, after postmortem examinations, that were suitable for transplantation. ${ }^{13}$ The parent group in the present study of families was self-selected, in that they had already agreed to participate in a research project related to the death of their infants. Therefore, other factors (religious or cultural beliefs or personal reasons) that might preclude families within the general population from participating in research projects of this nature were unlikely to affect our results. It is possible that the 24 families that did not respond to two letters and could not be contacted by telephone were actively avoiding the researchers. We considered this unlikely, since (a) the parents had previously been in a research project associated with SIDS and Kids, (b) few or none would have had a call-recognition facility and (c) there was a high acceptance rate among those who were contacted by telephone. We felt that it was more likely that contact details were no longer current. Since our main aim was to address the issue of consent for ongoing use of autopsy tissues retained from a previous study, our results are relevant and generalisable. This was evident in the finding that fewer of the study parents were distressed than was expected on the basis of the pilot group, who had mostly not discussed research of this nature or postmortem examinations. In the event, the piloted families expressed considerable distress and surprise, since they were considering the use of the postmortem tissue samples for the first time. They first had to "work through" their own reactions before considering the virtues or otherwise of such research.

This study has shown that research involving retained autopsy tissues is generally acceptable to the next of kin when they are sensitively approached and thoroughly informed by an experienced counsellor from a familiar and supportive organisation, in this case SIDS and Kids and VIFM. Even in this setting, where revisiting the catastrophic sudden loss of an infant will inevitably cause distress, most parents found the research to be

\section{3 setting up of advisory group} $(n=10)$

\begin{tabular}{|c|c|c|c|}
\hline \multicolumn{2}{|c|}{$\begin{array}{l}\text { Drafting of contact } \\
\text { documentation on } 5 \text { SIDS parent } \\
\text { advisers }\end{array}$} & \multicolumn{2}{|c|}{$\begin{array}{l}\text { Pilot contact documentation on } \\
5 \text { SIDS parent advisers }\end{array}$} \\
\hline \multicolumn{4}{|c|}{$\begin{array}{l}1991 \text { Victorian Sudden Infant Death Foundation epidemiological } \\
\text { study }(\mathrm{n}=107) \\
\text { Obtain current contact details }\end{array}$} \\
\hline $\begin{array}{l}\text { Contact details from } \\
\text { SIDS and Kids } \\
\qquad \begin{array}{l}n=30 \\
(28 \%)\end{array}\end{array}$ & $\begin{array}{r}\text { Contac } \\
\text { obtai } \\
\text { resea } \\
n \\
13\end{array}$ & $\begin{array}{l}\text { ct details } \\
\text { ined by } \\
\text { archers } \\
=42 \\
39 \% \text { ) }\end{array}$ & $\begin{array}{c}\begin{array}{c}\text { No contact } \\
\text { details available }\end{array} \\
\qquad \begin{array}{c}n=35 \\
(33 \%)\end{array}\end{array}$ \\
\hline \multicolumn{4}{|c|}{$\begin{array}{l}72 \text { families sent introduction letter from CEO of SIDS } \\
\text { and Kids, Victoria }\end{array}$} \\
\hline $\begin{array}{l}\text { Permission for } \\
\text { contact by VIFM }\end{array}$ & Permiss & sion refused & $\begin{array}{c}\text { No response to } 2 \\
\text { letters and no } \\
\text { contact } \\
\text { by telephone } \\
n=24 \\
(33 \%)^{*}\end{array}$ \\
\hline \multicolumn{4}{|l|}{ Obtained consent } \\
\hline $\begin{array}{l}\text { Consent form } \\
\text { returned } \\
\qquad \begin{array}{l}n=33 \\
(73 \%)\end{array}\end{array}$ & $\begin{array}{l}\text { Conse } \\
\text { not re }\end{array}$ & $\begin{array}{l}\text { ent form } \\
\text { eturned } \\
=6 \\
3 \% \text { ) }\end{array}$ & $\begin{array}{l}\text { Could not be } \\
\text { contacted by } \\
\text { VIFM } \\
n=6 \\
(13 \%)\end{array}$ \\
\hline
\end{tabular}

Figure 1 Flow chart showing subject participation in the survey in relation to the development and execution of the approach to SIDS parents regarding the asthma study. ${ }^{*} \%$ of families sent letters. CEO, chief executive officer; SIDS, sudden infant death syndrome; VIFM, Victorian Institute of Forensic Medicine. 
Table 1 Parent $(n=45)$ responses to telephone interviews

\begin{tabular}{lc}
\hline Response & Number* \\
\hline Very distressed & 2 \\
Distressed & 2 \\
Willing to help & 19 \\
Yes to asthma study at interview & 19 \\
Request all forms sent & 17 \\
Request to withhold postmortem information sheet & 7 \\
\hline
\end{tabular}

${ }^{*}$ More than one response recorded for some parents.

a positive outcome. Parents found that the use of tissue samples and information related to the death of their child in some way allowed something positive to come from the tragedy. It may be argued that making re-contact with parents in light of their loss is not ethical, given the inevitable distress. While it is not a legal requirement in the state of Victoria, and the decision to recontact families lay with VIFM, public sentiment regarding organ retention in Australia and abroad suggested to VIFM that future contact was necessary.

Views expressed by the subjects in this study regarding uses of stored tissue samples for research are similar to those obtained in other surveys. In a survey quoted in the National Institutes of Health study of participants who had previously provided tissue samples for research, ${ }^{14}$ only $7 \%$ refused any ongoing use, $26 \%$ stated they wanted to be contacted regarding further studies and $87 \%$ stated they would give consent for unlimited use of tissue for future research. This was unrelated to race, age, residence or the possibility of benefiting from the research. A survey of female breast cancer patients who had donated samples for research showed that the majority did not expect personal benefits and only a minority expressed concerns about the use of tissues for research that was not planned at the time of the original study. ${ }^{15}$ Similarly, a study of patients who had undergone a renal biopsy found that the "vast majority" were happy for the use of their biopsy tissue for research. ${ }^{16}$ Finally, our results are similar to those obtained in a telephone survey of family members regarding use of cadaveric tissues in a research protocol. ${ }^{17}$

In a recent discussion of the use of body tissues and the law, ${ }^{18}$ Charo stated, "Ultimately, the debate is less about whether the management of human tissue should be governed by property laws or by a more robust regulatory scheme than about the proper balance between respect for persons and the collective interest in promoting research involving human tissue." The balance of common good versus the potential distress and cost associated with unnecessary contact and individual private rights were discussed as part of a recent report regarding use of pathologic tissue samples. ${ }^{19}$ The present report addresses the need for respect for families and individuals (in this case SIDS infants and their parents) and the collective interest, with regard to SIDS and also to other diseases that affect many children, such as asthma. It should be noted that the approach outlined here was devised for parents who were aware that tissues had been retained and who had previously participated in research projects. As the response of our pilot group showed, this approach is not necessarily generalisable to all cases where retained tissues are involved.

Our experience in this study has again raised a number of issues that pertain to most studies using retained tissues. The concept of retained tissues gives rise to considerable concern to patients and their families, and a post hoc request may be initially distressing. If this is addressed in an open and supportive fashion, a significant proportion of individuals will be willing to give consent to immediate and long-term use of tissues for research, provided that the use of tissues is governed by a responsible body. The proportion of individuals that consent to studies is likely to vary according to social mores and religious beliefs. However, of those that do consent, most are happy for the use of tissues in ongoing studies, either at the initial approach or, as our study shows, at a later approach. As we found, a later approach is costly and very time consuming and results in the loss of contact of some previous participants. Increasingly, tissue banks are becoming an invaluable resource for epidemiological, genetic and pathological research and the usefulness of the tissues frequently extends well beyond the study for which they were first collected. Therefore, we recommend that all researchers who are seeking consent for the use of retained tissues should incorporate the opportunity of participants to give consent for future studies.

Acknowledgements: The authors would like to acknowledge Gillian Dite and the Centre for the Study of Mothers' and Children's Health for their contributions to the 1991-2 SIDS in Victoria case-control study, to Steven Cordner, Anne Giljohann, Vivienne Bateman and Nerida Mulvey for their contribution to the project and to the parent advisors for their invaluable insight. We would also like to acknowledge the passing of Kaarene Fitzgerald and recognise her contribution to the community of Victoria by founding SIDRF in 1977, after the death of her infant son. Ethics approval for this study was granted by the Sir Charles Gairdner Hospital and the Victorian Institute of Forensic Medicines ethics committees.

Funding: This project was supported by the Sir Charles Gairdner Hospital Research Foundation, which had no role in study design, data collection, analysis or interpretation or the publication of this manuscript.

Competing interests: None.

\section{REFERENCE}

1. Metters JS. Isaacs report. The investigation of events that followed the death of Cyril Mark Isaacs. The Crown, Department of Health, Norwich. 2003:1-395. http://www. archive2.official-documents.co.uk/reps/report/isaacs report.pdf (accessed 2 July 2008).

2. Redfern M, Keeling J, Powell E. The Royal Liverpool Children's inquiry report, House of Commons, 2001. London: Stationery Office, 2001. http://www.rlcinquiry.org.uk/ index.htm (accessed 2 July 2008).

3. Walker B. Inquiry into matters arising from the post mortem and anatomical examination practices of the Institute of Forensic Medicine. Sydney: Government of the State of New South Wales, 2001. http://www.health.nsw.gov.au/pubs/i/forensic/ (accessed 2 July 2008)

4. Anon. Autopsy and the use of tissues removed at autopsy. The Royal College of Pathologists of Australasia. Med J Aust 1994;160:442-4.

5. Trouet C. New European guidelines for the use of stored human biological materials in biomedical research. J Med Ethics 2004;30:99-103.

6. Australian Health Ethics Committee. Organs retained at autopsy-ethical and practical issues. Canberra: National Health and Medical Research Council, 2001. http://www.nhmrc.gov.au/publications/synopses/e41syn.htm (accessed 2 July 2008).

7. National Health and Medical Research Council, National statement on ethical conduct in research involving humans. Commonwealth of Australia, Canberra. 1999:1-80. http://www.nhmrc.gov.au/publications/synopses/_files/e35.pdf (accessed 2 July 2008).

8. Steinberg KK. Ethical challenges at the beginning of the millennium. Stat Med 2001;20:1415-9. Unpublished manuscript.

9. Dite G. SIDS in Victoria: case-control study: report of the second year of data collection May 1991 to April 1993. Unpublished manuscript. Victoria, Australia: Sudden Infant Death Research Foundation, 1993. http://203.25.172.154/details. asp?id = 1399 (accessed 2 July 2008). Full text available on application in writing to: The Librarian, SIDS and Kids Victoria, 1227 Malvern Road, Malvern, Victoria 3144, Australia; librarian@sidsandkids.org.

10. Elliot J, Vullermin P, Carroll N, et al. Increased airway smooth muscle in sudden infant death syndrome. Am J Respir Crit Care Med 1999; 160:313-6.

11. Elliot J, Vullermin P, Robinson P. Maternal cigarette smoking is associated with increased inner airway wall thickness in children who die from sudden infant death syndrome. Am J Respir Crit Care Med 1998;158:802-6.

12. Elliot JG, Carroll NG, James AL, et al. Airway alveolar attachment points and exposure to cigarette smoke in utero. Am J Respir Crit Care Med 2003;167:45-9.

13. Rodriguez-Villar C, Ruiz-Jaramillo MC, Paredes D, et al. Telephone consent in tissue donation: effectiveness and efficiency in postmortem tissue generation. Transplant Proc 2007;39:2072-5. 
14. Minkel JR. Uninformed consent. Sci Am 2006;295:22-4.

15. Kaphingst KA, Janoff JM, Harris LN, et al. Views of female breast cancer patients who donated biologic samples regarding storage and use of samples for genetic research. Clin Genet 2006;69:393-8.

16. Furness PN, Nicholson ML. Obtaining explicit consent for the use of archival tissue samples: practical issues. J Med Ethics 2004; 30:561-4.
17. Womack C, Jack AL. Family attitudes to research using samples taken at coroner's postmortem examinations: review of records. BMJ 2003;327:781-2.

18. Charo RA. Body of research—ownership and use of human tissue. N Engl J Med 2006;355:1517-9.

19. Zeps N, lacopetta BJ, Schofield L, et al. Waiver of individual patient consent in research: when do potential benefits to the community outweigh private rights? Med J Aust 2007;186:88-90.

\section{Need a helping hand with your career choices?}

If you need to take stock, get some career advice or find out about the choices available to you then the BMJ Careers Fair is the place to do it. You can find out about how best to present yourself to potential employers, polishing up your CV, working abroad, locum working and much more.

BMJ Careers Fairs - dates for your diary

3-4 October 2008 - Business Design Centre, London

10-11 October 2008 - Thinktank, The Science Museum, Birmingham - working in partnership with the West Midlands Deanery

Register now at bmjcareersfair.com

BMJ Careers 